\title{
REGALÍAS Y POBREZA EN \\ EL CARIBE COLOMBIANO: ¿MOMENTO PARA UNA ALTERNATIVA FOCALIZADA?
}

Lina Marcela Moyano*

Philip William Wright**

- ste artículo evalúa si el sistema de regalías adoptado en 2012 ha Etenido un impacto significativo sobre la pobreza en la región Caribe, la cual tiene una alta concentración de pobres ${ }^{1}$. Esto es importante por dos razones. Primera, el nuevo sistema redujo la participación privilegiada de los departamentos productores de recursos no renovables y abrió la oportunidad para corregir las desigualdades entre regiones, entre áreas urbanas y rurales, y entre personas. Segunda, para el desarrollo del país es esencial enfrentar estas desigualdades; aún más con la posible terminación del conflicto armado.

Además, la desigualdad en Colombia es mayor que en otros países de nivel de desarrollo similar. A finales de 2012, el Banco Mundial ubicó a Colombia como el séptimo país más desigual del mundo y señaló que la reducción de la incidencia de la pobreza ha sido lenta. "Nuestros cálculos muestran que si Colombia tuviera la misma distribución de ingreso que Perú, la pobreza habría sido diez puntos porcentuales más baja que hoy, i.e., alrededor del 25 por ciento" (Mollar, 2012). En la región Caribe, formada por 8 de los 32 departamentos del país y con cerca de 10 millones de habitantes (casi una quinta

\footnotetext{
* Economista, asistente de investigación en el Observatorio del Caribe Colombiano, Cartagena, Colombia, [1moyano@ocaribe.org].

** Doctor en Economía, director científico del Observatorio del Caribe Colombiano, Cartagena, Colombia, [pwright@ocaribe.org]. Los autores agradecen el apoyo de Colciencias en la financiación de este trabajo. Fecha de recepción: 2 de febrero de 2015, fecha de modificación: 17 de julio de 2015, fecha de aceptación: 12 de mayo de 2016. Sugerencia de citación: Moyano, L. M. y P. W. Wright. "Regalías y pobreza en el Caribe colombiano: ¿momento para una alternativa focalizada?", Revista de Economía Institucional 18, 34, 2016, pp. 201-227. DOI: http://dx.doi.org/10.18601/01245996.v18n34.12

${ }_{1}$ Esta región está formada por ocho departamentos: Córdoba, Sucre, Bolívar, Atlántico, Magdalena, Cesar, La Guajira, y San Andrés y Providencia.
} 
parte del total), la concentración espacial de la pobreza escasamente ha cambiado en cuatro décadas (Galvis y Meisel, 2010).

Trabajos anteriores sobre el tema analizan el impacto del sistema anterior sobre la pobreza y encuentran que poco o nada la redujo (Rojas, 2014; Cuéllar y Castellanos, 2011; Garcés y Espitia, 2009). Otros autores encuentran que la equidad en la asignación de las regalías ha mejorado con respecto al sistema anterior (Bonet y Urrego, 2014). Pero no consideran si, por diseño o por impacto, el nuevo sistema ha tenido un efecto significativo sobre la pobreza.

El trabajo consta de cuatro partes. En la primera se examina el diseño del nuevo sistema ex ante y se evalúa el grado en que proporciona recursos que podrían aliviar directamente la pobreza. ¿Qué porcentaje de las regalías está potencialmente disponible para aliviar directamente la pobreza y qué porcentaje de esos recursos llega a la región Caribe? En la segunda se revisa el uso de esos recursos buscando impactos ex post sobre la pobreza. Este ejercicio tiene dos dimensiones: un análisis de la asociación entre la distribución de las regalías asignadas por municipio y la incidencia de la pobreza en estos municipios, y una clasificación de los proyectos financiados con regalías en la región, para evaluar su probable impacto directo sobre la pobreza. Este ejercicio permite considerar el impacto de la inversión de regalías a nivel municipal y departamental, como se explica más adelante. En la tercera se revisa la creciente literatura sobre distribución directa de las regalías a los individuos como alternativa más efectiva para mejorar la vida de los pobres. Por último se evalúa el posible impacto de esta alternativa sobre la pobreza en la región.

\section{EL DISEÑO DEL NUEVO SISTEMA: EXPECTATIVAS EX ANTE}

\section{EL SISTEMA ANTIGUO}

E1 sistema anterior, vigente hasta 2011, diferenciaba entre "regalías directas" y "regalías indirectas". De acuerdo con la Ley 141 de 1994, solo recibían regalías directas los departamentos y municipios que participaban en la producción o transporte de recursos no renovables; un $80 \%$ de las regalías distribuidas entre 1994 y 2009 (Echeverry et al., 2011). Inicialmente se especificó que un mínimo del $80 \%$ de las regalías se debían destinar para llegar a la cobertura mínima de los servicios públicos esenciales, pero en 2002 la Ley 756 estipuló que al menos el 60\% (para los departamentos) o el 75\% (para los municipios) se debía destinar a mejorar dicha cobertura y el indicador de mortalidad infantil, en caso de que no se hubiese alcanzado el nivel 
mínimo. Hay evidencia de que, en algunos casos, las regalías se gastaron de modo ilegítimo o con poca preocupación por las mejoras sociales (Ministerio de Minas y Energía, 2011; Candelo et al., 2010; Hernández, 2010). Ese problema fue muy grave en la región Caribe, donde se reportó el 56\% de los usos irregulares de las regalías directas entre 2005 y 2010 (Echeverry et al., 2011, 36).

Las regalías indirectas estaban disponibles para todos los departamentos y municipios mediante solicitud al Fondo Nacional de Regalías. Entre los criterios para financiar proyectos con estos recursos se contaban la densidad de población y la incidencia de la pobreza. Pero las regalías indirectas solo abarcaron el $20 \%$ del total de las que se distribuyeron entre 1994 y 2009, ningún imperativo social específico rigió la inversión de estos recursos y su eficacia social fue cuestionada por el Departamento Nacional de Planeación (DNP, 2008).

La conclusión de los trabajos citados de que el antiguo sistema no tuvo un impacto visible sobre la pobreza no es entonces sorprendente. El sistema anterior concentraba los recursos en los departamentos productores de hidrocarburos. Cuatro de ellos -Arauca, Casanare, La Guajira y Meta- recibieron el 55,7\% de las regalías entre 1994 y 2009, cuya población es apenas el 5\% del total del país (Echeverry et al., 2011). Garcés y Espitia (2009), recurriendo al análisis de conglomerados en el periodo 1993 a 2005, también constatan que el sistema anterior no tuvo un impacto significativo sobre los indicadores económicos y sociales de los departamentos donde la participación de las regalías en los ingresos y gastos totales era muy superior a la media nacional. Este estudio reveló que la mayoría de los departamentos de la región Caribe tenía indicadores de desarrollo (NBI y PIB per cápita) inferiores a la media nacional, pero la contribución de las regalías a sus finanzas era baja o nula. Debido a los resultados de esos estudios la reforma del sistema de regalías fue una prioridad inmediata en los primeros meses de la presidencia de Juan Manuel Santos (2010-2014).

\section{EL NUEVO SISTEMA}

E1 nuevo sistema, llamado "Sistema General de Regalías" fue establecido por el Acto Legislativo 05 de 2011 y regulado por la Ley 1530 de 2012 con el fin de mejorar la equidad en la distribución de las regalías para promover el desarrollo regional y la competitividad. La Ley 1530 también daba prioridad a la población pobre en la distribución de las regalías. E1 nuevo sistema, que empezó a funcionar en 2012, clasificó la distribución de las regalías en nueve categorías: 1 . Ahorro pensional de las entidades territoriales; 2 . Fondo de ciencia, tecnología 
e innovación (FCTI); 3. Fondo de Ahorro y Estabilización (FAE); 4. Asignaciones directas para departamentos productores, municipios y puertos marítimos y fluviales; 5. Fondo de Desarrollo Regional (FDR); 6. Fondo de Compensación Regional (FCR); 7. Fiscalización de la exploración y explotación de yacimientos, y conocimiento y cartografía geológica del subsuelo; 8. Funcionamiento del sistema de monitoreo, seguimiento, control y evaluación (al que se asignó hasta el 1\% del total de regalías), y 9. Funcionamiento del sistema general (al que se asignó hasta el 2\%).

Para estimar ex ante un impacto potencial significativo del nuevo sistema sobre la pobreza, el primer paso es determinar la proporción de regalías que se destina a los dos componentes que se pueden usar para combatirla: el FDR y el FCR, aunque la prioridad del primero es la competitividad. El segundo es particularmente importante porque su propósito es ayudar a cerrar la brecha de las regiones pobres. Este ejercicio tiene tres dificultades.

1. La distribución de los recursos se presenta en términos de porcentajes de residuos (gráfica 1). En la primera etapa de la distribución tienen prioridad tres categorías: $10 \%$ para el FCTI, 10\% para los déficits pensionales y hasta un 30\% para el FAE. Esto deja un residuo mínimo del 50\% para las demás categorías, del cual se destinaría un $50 \%$ a los fondos regionales y el otro $50 \%$ a las asignaciones directas a entidades productoras durante el primer año de transición (2012) de la reducción de asignaciones directas ${ }^{2}$. Del 50\% a los fondos regionales, el 60\% va al FCR, la fuente de financiación que quizá sea utilizada para combatir la pobreza (como muestran los sus criterios de distribución de la gráfica 1).

2. Como se mencionó, hay un periodo de transición diseñado para mitigar el impacto de la redistribución de las regalías entre entidades productoras. La suma disponible para “Compensación Regional” aumenta lentamente mientras que las asignaciones directas se reducen del 50\% en 2012 al 20\% en 2014, año final de la transición.

3. Los recursos para el FCR también están afectados por la variación de los que se destinan al FAE cada año (hasta el 30\% del primer nivel de distribución). Criterios similares afectan la suma que recibe el FDR, el cual también tiene un elemento de política anti pobreza en sus reglas de distribución.

Los cuadros 1 y 2 muestran la distribución de las regalías entre categorías y rubros de gasto para establecer el porcentaje disponible para

\footnotetext{
2 E1 término "entidades productoras" incluye todos los departamentos y municipios involucrados en la producción o transporte de recursos no renovables.
} 
Gráfica 1

Distribución de las regalías después de 2012

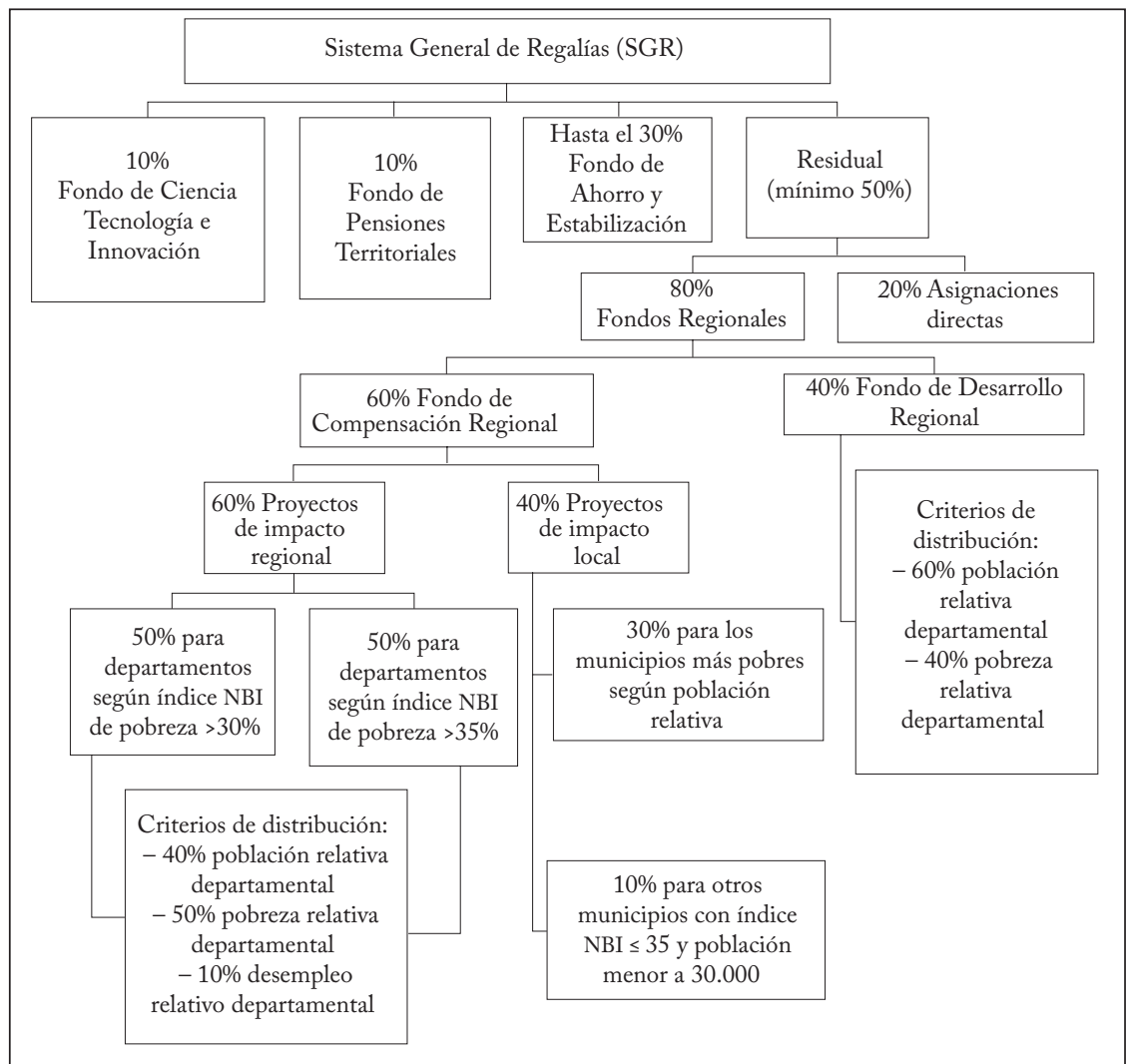

Nota: NBI = necesidades básicas insatisfechas, un índice de pobreza basado en la cobertura de servicios públicos y la calidad de la vivienda.

Fuente: Acto Legislativo 05 de 2011 y Ley 1530 de 2012, elaboración propia.

financiar proyectos anti pobreza a través del Fondo de Compensación Regional y el Fondo de Desarrollo Regional. Aunque existe otro factor que afecta el cálculo de este porcentaje: el monto asignado al Fondo de Desarrollo Regional difiere del monto legalmente programado, debido al piso límite en la reducción de asignaciones directas que las entidades productoras deben recibir con el nuevo sistema frente al anterior ${ }^{3}$. Por ello se muestran la distribución "actual” y la "estándar" que ordena la legislación. También existe la opción de usar las regalías

${ }^{3}$ Según el Acto Legislativo 05 de 2011, si la distribución directa a las entidades productoras se reduce por debajo del $50 \%$ del valor real del promedio anual de la distribución directa recibida entre 2007 y 2010, tienen derecho a recibir un porcentaje adicional como compensación, a costa de la suma asignada al Fondo de Desarrollo Regional del respectivo departamento, como sucedió en 2012. 
totales para calcular la distribución o el total menos la suma destinada a "otros", categoría que incluye los gastos de fiscalización, monitoreo y funcionamiento del sistema, y una suma para Cormagdalena (Bonet y Urrego, 2014, 5).

Cuadro 1

Distribución de las regalías, 2012

(Millones de pesos corrientes)

\begin{tabular}{lccc}
\hline Categoría & Monto & $\begin{array}{c}\text { Proporción } \\
\text { (actual) }\end{array}$ & $\begin{array}{c}\text { Proporción } \\
\text { (estándar) }\end{array}$ \\
\hline Fondo de Ciencia, Tecnología e & $869.007,5$ & 10,0 & 10,0 \\
Innovación & & & \\
Fondo de Pensiones Territoriales & $869.007,5$ & 10,0 & 10,0 \\
Fondo de Ahorro y Estabilización & $1.738 .015,0$ & 20,0 & 20,0 \\
Asignaciones directas & $3.001 .485,0$ & 34,5 & 32,5 \\
Fondo de Compensación Regional & $1.433 .862,4$ & 16,5 & 16,5 \\
Fondo de Desarrollo Regional & $778.697,7$ & 9,0 & 11,0 \\
Otros (monitoreo, fiscalización, etc.) & $409.480,0$ & - & - \\
\hline Total (sin otros) & $9.099 .555,1$ & - & - \\
Total (sin & $8.690 .075,1$ & 100,0 & 100,0 \\
\hline
\end{tabular}

Fuente: SGR (2014), cálculos de los autores.

El cuadro 1 detalla la distribución de las regalías en 2012 y muestra que la suma destinada a "otros" fue de unos 400 mil millones de pesos, $4,5 \%$ del total. Utilizando el total neto sin "otros" (como hace el cálculo oficial), solo el $16,5 \%$ se dirigió a aliviar la pobreza a través del FCR: cerca de 1,4 billones de pesos, unos 797 millones de dólares a la tasa de cambio promedio de 2012. El FDR solo recibió el 9\% de las regalías. Esta distribución se calculó sin que el Fondo de Ahorro y Estabilización hubiera alcanzado el porcentaje máximo, 30\%: si esto hubiese sucedido, las proporciones disponibles para el FCR y el FDR habrían sido proporcionalmente menores.

Cuadro 2

Distribución de las regalías, 2013-2014

(Millones de pesos corrientes)

\begin{tabular}{lcc}
\hline Categoría & \multicolumn{1}{c}{ Monto } & Proporción (actual) \\
\hline Fondo de Ciencia, Tecnología e Innovación & $1.675 .129,8$ & 10,0 \\
Fondo de Pensiones Territoriales & $1.675 .129,8$ & 10,0 \\
Fondo de Ahorro y Estabilización & $3.172 .654,6$ & 18,9 \\
Asignaciones directas & $3.630 .993,5$ & 21,7 \\
Fondo de Compensación Regional & $3.958 .434,2$ & 23,6 \\
Fondo de Desarrollo Regional & $2.638 .956,1$ & 15,8 \\
Otros (monitoreo, fiscalización, etc.) & $974.943,3$ & - \\
\hline Total & $17.726 .241,3$ & - \\
Total (sin otros) & $16.751 .298,1$ & 100,0 \\
\hline
\end{tabular}

Fuente: SGR (2014), cálculos de los autores. 
E1 cuadro 2 muestra la distribución de las regalías en 2013-2014, utilizando el mismo procedimiento. Se observa un aumento importante en la proporción asignada al FCR y al FDR, debido principalmente a una reducción programada de las asignaciones directas, y también a una pequeña reducción en la participación del Fondo de Ahorro y Estabilización (18,9\%, frente al 20\% en 2012 y un máximo legal del 30\%). E1 FCR recibió el 23,6\% en 2013-2014 y el FDR, el 15,8\%. Pero la financiación que puede cambiar potencialmente el paisaje de la pobreza es aún menor a la mitad del total y correspondía a sumas anuales de 1.059 millones de dólares (compensación regional) y 706 millones de dólares (desarrollo regional), a la tasa de cambio promedio de 2013.

\section{INVERSIONES CON EL NUEVO SISTEMA: IMPACTO EX POST SOBRE LA POBREZA}

La sección anterior indica que hay un esfuerzo para destinar, al menos a través del FCR, una proporción de recursos de las regalías $(23,6 \%)$ a los departamentos y municipios más pobres, aplicando los criterios de la gráfica 1. Esto no significa que esos recursos se distribuyan estrictamente según las necesidades, como muestran los indicadores de pobreza, ni que se destinen a financiar proyectos que alivien directamente la pobreza. Este aspecto ex post del impacto sobre la pobreza del nuevo sistema de regalías es el tema de esta sección y tiene dos aspectos. Primero se examina la distribución de las regalías per cápita por municipio en la región y se compara con los indicadores de pobreza municipal para establecer si existe una relación positiva entre la pobreza municipal y la asignación per cápita de regalías a los municipios. Luego se examinan las inversiones actuales para determinar hasta qué punto los proyectos aprobados para financiar con las regalías tienen un impacto directo sobre la pobreza.

Con relación al primer aspecto, en el estudio de Bonet y Urrego ya mencionado se hizo un ejercicio similar, pero a nivel departamental y con el fin principal de comparar el nuevo sistema con el anterior. En ese trabajo se encontró que el nuevo sistema es (casi inevitablemente) más equitativo que el anterior, y que hay una relación positiva entre asignación per cápita de regalías e incidencia de la pobreza a nivel departamental. Nuestro trabajo examina el grado en que las regalías están llegando a la población pobre en la región Caribe, y por ello hace énfasis en el nivel municipal de las asignaciones y en la inversión de las regalías a nivel municipal y departamental en esta región. 


\section{EQUIDAD EN LA DISTRIBUCIÓN DE LAS REGALÍAS EN LA REGIÓN CARIBE}

En este contexto general examinemos lo que ha sucedido en la región Caribe. En el periodo 2013-2014 se le asignaron 5,15 billones de pesos por regalías, unos 2.800 millones de dólares, el 31\% del total. Un porcentaje potencialmente positivo desde el punto de vista de la redistribución porque es mayor que el de la población (21\% del total). De esa suma, el $75 \%$ se asignó a los departamentos, el $24 \%$ a los municipios y el $1 \%$ restante a las corporaciones autónomas regionales (SGR, 2014a). La gran diferencia entre la participación departamental y la municipal se debe a que los departamentos participan en todos los fondos del sistema, mientras que los municipios solo participan en el fondo de pensiones territoriales, en las asignaciones directas y en el FCR, aunque solo en un 40\% de este último (gráfica 1).

\section{Regalías a los municipios e incidencia de la pobreza}

La gráfica 2 muestra la relación entre las regalías per cápita (asignaciones directas + pensiones + asignaciones al FCR) recibidas por los 197 municipios de la región, y su nivel de pobreza según el Índice de Necesidades Básicas Insatisfechas de $2011^{4}$. Aplicando el coeficiente de correlación por rangos de Spearman se encuentra una débil relación positiva entre asignaciones per cápita e incidencia de la pobreza $(0,3617 \text {, significativo al } 1 \%)^{5}$. La debilidad de la relación se manifiesta más concretamente al comparar dos municipios con un nivel de regalías per cápita similar, Carmen de Bolívar, el 93\% de cuya población tiene necesidades básicas insatisfechas, y San Juan del Cesar, donde la proporción es de un 45\%. Una distribución equitativa habría asignado una suma per cápita más alta a Carmen de Bolívar que a San Juan del Cesar. Además, ninguno de esos municipios recibió asignaciones directas que podría haber mejorado la distribución.

Cabe resaltar dos aspectos adicionales de la relación entre indicadores de pobreza municipal y asignación de regalías. 1. Es tal la pobreza de los municipios de la región que solo cinco municipios no recibieron recursos del FCR: Barranquilla y Soledad (Atlántico), Valledupar (Cesar), Santa Marta (Magdalena) y Cartagena (Bolívar),

${ }^{4}$ Este es una actualización rudimentaria de un índice construido con datos del censo de 2005. Es la única medida de pobreza disponible a nivel municipal y la que se usa para asignar regalías según los umbrales de pobreza. No es indispensable que el índice NBI esté actualizado porque aquí se analiza la posición relativa de los municipios y no su nivel absoluto de pobreza. El uso de este índice sería problemático si hubiese habido cambios importantes en esas posiciones, lo que no parece haber ocurrido.

5 Se emplea este coeficiente de Spearman en vez del coeficiente de Pearson porque los datos no siguen una distribución normal. 
Gráfica 2

Regalías per cápita, Región Caribe y porcentaje de personas con NBI

2013-2014

(Millones de pesos)

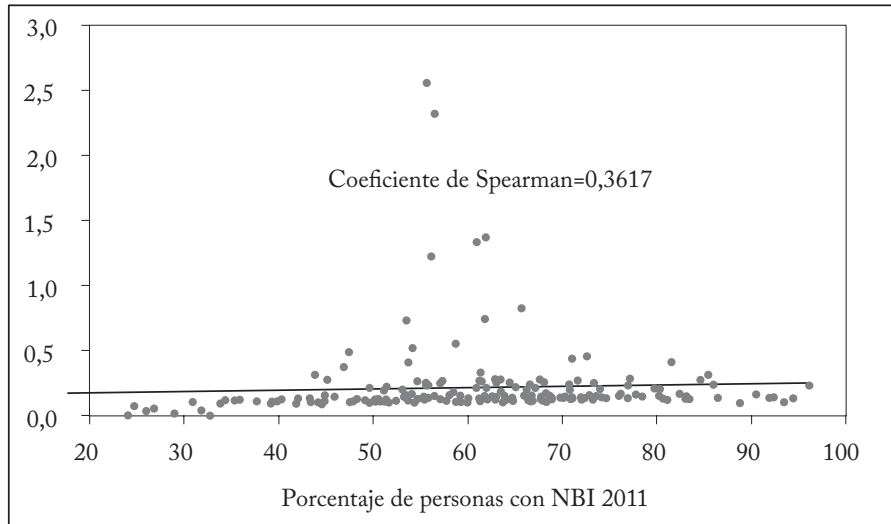

Nota: para calcular las regalías per cápita, los datos de la distribución bienal 2013-2014 se dividieron por la población proyectada por el DANE para 2013.

Fuente: SGR (2014) y DANE (2014a), cálculos de los autores.

capitales departamentales excepto Soledad. 2. Los municipios con mayor asignación per cápita -como La Jagua de Ibirico y Becerril en el Cesar y Albania en La Guajira- son entidades productoras y, por ende, reciben regalías directas. Se destacan en la gráfica 2 como datos atípicos: el $88 \%$ de los municipios de los dos quintiles más altos de la distribución son entidades productoras, con asignaciones directas. Esta distribución refleja una clara inequidad entre ricos y pobres en recursos no renovables e ilustra por qué Amilkar Acosta (2012), ex senador y ex ministro de Energía, estuvo en desacuerdo con una fuerte reducción de las asignaciones directas: reducir los ingresos de las entidades productoras al nivel modal tendría un impacto importante sobre el bienestar de estos municipios y departamentos.

Considerando únicamente la distribución total de regalías, el nuevo sistema solo muestra una relación moderadamente positiva entre asignación de regalías y extensión de la pobreza en la región. Esto obedece en parte a que la distribución total no se basa en indicadores de pobreza, y el componente que sí los considera se basa en umbrales $\mathrm{y}$ no en una escala calibrada por niveles de pobreza.

\section{Regalías del FCR a los municipios}

E1 componente con más potencial anti pobreza del nuevo sistema parece ser el FCR. El siguiente paso es entonces examinar el grado de equidad en la distribución de este fondo a los 197 municipios de la 
región y compararla con el resultado nacional. Como referencia, cabe mencionar que en 2013-2014 estos municipios recibieron el 33,5\% de los recursos del Fondo y los departamentos el 36,4\%, más que su participación en la población nacional (SGR, 2014).

\section{Gráfica 3}

Regalías per cápita del FCR a la región y porcentaje de personas con NBI 2013-2014 (Miles de pesos)

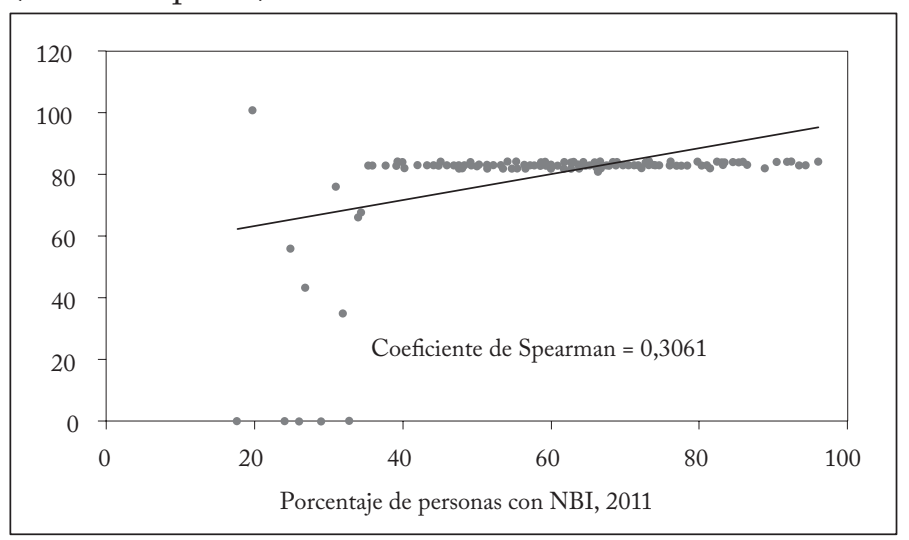

Nota: para calcular la distribución per cápita del FCR se dividieron los datos de la distribución bienal 2013-2014 por la proyección de población para 2013.

Fuente: SGR (2014) y DANE (2014a), cálculos de los autores.

Pero la gráfica 3 también muestra una relación débil entre regalías del FCR y pobreza: el 35\% o más de los habitantes del $94 \%$ de los municipios tienen necesidades básicas insatisfechas y la suma que distribuye el Fondo varía en un rango muy estrecho (80.000 a 85.000 pesos per cápita). De nuevo, si se comparan dos municipios con una asignación per cápita similar del Fondo: Colosó (Sucre) tenía un $85,1 \%$ de la población con necesidades básicas insatisfechas mientras que Tubará (Atlántico) solo tenía un 35,9\%.

También se encuentra que la relación entre regalías per cápita del Fondo a los municipios e incidencia de la pobreza es algo más débil frente a la distribución total, que incluye asignaciones directas y financiación de los déficits pensionales. Esta paradoja obedece a una relación más fuerte entre asignaciones per cápita del Fondo de Pensiones Territoriales e incidencia de la pobreza (Spearman 0,4363), que refuerza el efecto positivo sobre la distribución total a los municipios.

El resultado a nivel nacional también es débil, pero un poco más positivo que para la región Caribe. Además, una proporción menor 
de los municipios a nivel nacional, el 65\%, recibe sumas per cápita del FCR entre 80.000 y 85.000 pesos. Pero el aspecto más llamativo de las diferencias entre el nivel nacional y la región Caribe no guarda relación directa con el tema principal de este trabajo: a un grupo de municipios menos pobres se le asignan regalías muy variables, es decir, el nuevo sistema permite que municipios con menor incidencia de la pobreza reciban aportes relativamente altos.

Gráfica 4

Regalías per cápita del FCR en el país y personas con NBI

2013-2014

(Miles de pesos)

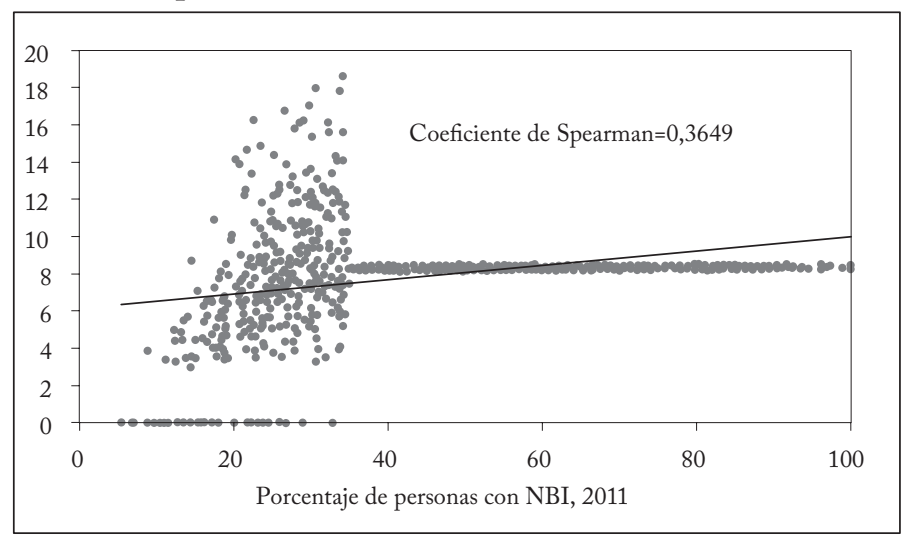

Nota: para calcular la asignación per cápita del FCR se dividieron los datos de la distribución bienal 2013-2014 por la proyección de población para 2013.

Fuente: SGR (2014) y DANE (2014a), cálculos de los autores.

Una conclusión general con respecto a la distribución municipal expost de las regalías es que hay una relación directa positiva entre asignación per cápita y nivel de pobreza, pero débil. Los criterios de distribución no concuerdan con las necesidades de las comunidades más pobres: solo un 30\% de la distribución de regalías a nivel municipal considera criterios relacionados con la pobreza (el FCR), pero no se utiliza una calibración suficientemente precisa con indicadores de pobreza ${ }^{6}$.

\section{PROYECTOS FINANCIADOS CON REGALÍAS Y POBREZA EN LA REGIÓN}

Hasta ahora se ha considerado la relación entre regalías y pobreza examinando el potencial ex ante y la distribución expost, y aún no se han analizado las inversiones financiadas con regalías y la relación

\footnotetext{
${ }^{6}$ La distribución del fondo para cubrir los déficits pensionales departamentales o municipales, FONPET, sigue criterios de equidad pero no permite financiar proyectos.
} 
entre esas inversiones y la pobreza. Antes cabe aclarar que, en el nuevo sistema, recibir una asignación no significa que esté disponible inmediatamente para financiar cualquier proyecto que elija un municipio o departamento. La inversión tiene que dedicarse a proyectos aprobados por los Órganos Colegiados de Administración y Decisión (OCAD) nacional, regionales o municipales, en los que hay representación de diferentes niveles de gobierno y miembros comisionados (Ley 1530 de 2012, art. 6).

Cuadro 3

Distribución de los proyectos aprobados en los OCAD por sector, 2012-15 de septiembre de 2014

\begin{tabular}{|c|c|c|c|c|c|c|}
\hline \multirow[b]{2}{*}{ Sector } & \multicolumn{3}{|c|}{ Nacional } & \multicolumn{3}{|c|}{ Región Caribe } \\
\hline & $\begin{array}{c}\text { Número } \\
\text { de } \\
\text { proyectos }\end{array}$ & $\begin{array}{c}\text { Porcentaje } \\
\text { de } \\
\text { proyectos }\end{array}$ & $\begin{array}{c}\text { Porcentaje } \\
\text { del valor } \\
\text { aprobado }\end{array}$ & $\begin{array}{l}\text { Número } \\
\text { de } \\
\text { proyectos }\end{array}$ & $\begin{array}{c}\text { Porcentaje } \\
\text { de } \\
\text { proyectos }\end{array}$ & $\begin{array}{c}\text { Porcentaje } \\
\text { del valor } \\
\text { aprobado }\end{array}$ \\
\hline Transporte & 1.809 & 29,4 & 30,2 & 514 & 31,8 & 30,3 \\
\hline Vivienda, ciudad y territorio & 1.083 & 17,6 & 15,6 & 204 & 12,6 & 10,8 \\
\hline Otros & 784 & 12,7 & 14,9 & 222 & 13,7 & 16,9 \\
\hline Educación & 703 & 11,4 & 12,7 & 199 & 12,3 & 13,8 \\
\hline Cultura, deporte y recreación & 676 & 11,0 & 4,2 & 216 & 13,4 & 6,4 \\
\hline Agricultura & 328 & 5,3 & 4,1 & 59 & 3,6 & 2,3 \\
\hline Inclusión social y reconciliación & 317 & 5,1 & 2,6 & 76 & 4,7 & 2,2 \\
\hline Ciencia y tecnología & 236 & 3,8 & 12,2 & 52 & 3,2 & 12,9 \\
\hline Ambiente y desarrollo sostenible & 220 & 3,6 & 3,5 & 75 & 4,6 & 4,5 \\
\hline Total & 6.156 & 100 & 100 & 1.617 & 100 & 100 \\
\hline
\end{tabular}

Nota: Otros incluye varias categorías con participaciones muy pequeñas.

Fuente: SGR (2014b), cálculos de los autores.

Para relacionar los proyectos financiados con regalías y alivio de la pobreza se procede en dos etapas, teniendo en cuenta que se considera el total de regalías aprobadas para los departamentos y los municipios. En primer lugar, el cuadro 3 resume la distribución de las regalías aprobadas para financiar proyectos desde inicios del nuevo sistema, en 2012, hasta septiembre de 2014: 1.617 de los 6.156 proyectos aprobados corresponden a la región Caribe; por un valor de 4,4 billones de pesos, 31,4\% de total nacional, mayor que su proporción de habitantes. Pero su destinación, a nivel nacional y en la región, no augura un impacto directo y significativo sobre la pobreza. Como se observa en el cuadro, el tipo de inversión más grande es el de transporte (principalmente en infraestructura). Solo una pequeña parte corresponde a categorías de mayor impacto potencial sobre la pobreza (vivienda e inclusión social) y la inversión en el sector agrícola, donde hay gran concentración de personas pobres, es solo el 2,3\% del total, menor que el promedio nacional (4,1\%).

En segundo lugar, se examinan los proyectos aprobados para financiar con regalías en la región con el fin de calificarlos por su 
probable impacto directo e inmediato sobre la pobreza, identificando la financiación con regalías dirigida directamente a la población caribeña pobre y vulnerable. Esta calificación toma en cuenta el título del proyecto -lo que puede parecer un método tosco-, pero el título da información suficiente para distinguir los proyectos que benefician directamente a los pobres de los que no los benefician directamente. En la calificación se incluyeron los proyectos que buscan mejorar componentes específicos del índice de NBI: acceso a servicios públicos, dependencia económica, inasistencia escolar, vivienda subnormal y hacinamiento crítico). También se incluyen los proyectos de salud que buscan mejorar de modo directo la salud y el bienestar de las personas pobres, como los de mejoramiento de la nutrición.

Hay proyectos en los que se puede identificar el número específico de familias pobres y vulnerables, por ejemplo:

- Mejoramiento socioeconómico para la seguridad alimentaria de 250 familias campesinas mediante modelos piloto de producción de hortalizas, plátano y fruta en El Copey, Agustín Codazzi, La Paz, Manaure (Cesar).

Proyectos que buscan mejorar la nutrición más directamente, a menudo como componente de una estrategia para mejorar la asistencia escolar, por ejemplo:

- Programa nutricional y alimentario para las comunidades de los resguardos indígenas El Cerro, Lomamato y Rodeíto el Pozo en el municipio de Hatonuevo (La Guajira).

- Desayuno, almuerzo y meriendas a los estudiantes de las instituciones educativas urbanas y rurales de Ciénaga (Magdalena).

Proyectos que facilitan el transporte escolar, por ejemplo:

-Transporte escolar gratuito a los estudiantes de las instituciones educativas oficiales de la zona de difícil acceso en Coveñas (Sucre).

Proyectos que buscan introducir o mejorar un servicio público, por ejemplo:

- Construcción de redes eléctricas en los barrios Ciudad Bolívar y Ciudadela La Paz del municipio de Santa Rosa del Sur (Bolívar).

- Construcción de la conexión del servicio de gas natural domiciliario para estratos 1 y 2 en Valencia de Jesús, Aguas Blancas y Mariangola, Valledupar (Cesar).

- Construcción de un sistema de alcantarillado, separadores y un estanque de estabilización en Polonuevo (Atlántico).

$\mathrm{Y}$ proyectos para mejorar o construir vivienda nueva para los pobres, por ejemplo: 
- Construcción de viviendas de interés social en San Alberto, Aguachica, Curumaní, Astrea, Becerril, San Diego y Gamarra (Cesar). - Mejoramiento de viviendas en el corregimiento San Blas-Simití (Bolívar). Por su ubicación, este proyecto es para una comunidad pobre.

De modo que no es difícil separar este tipo de proyectos de aquellos que no tienen un impacto directo sobre la pobreza, como los 514 proyectos aprobados para mejorar la infraestructura de transporte.

\section{Cuadro 4}

Proyectos aprobados para financiar desde 2012

Inversión nacional, regional y para erradicar la pobreza

(Miles de millones de pesos)

\begin{tabular}{lrr}
\hline Categoría & $\begin{array}{c}\text { Número de } \\
\text { proyectos }\end{array}$ & $\begin{array}{r}\text { Valor } \\
\text { aprobado }\end{array}$ \\
\hline Proyectos aprobados en la región & 1.617 & $4.461,1$ \\
Proyectos aprobados en el país & 6.156 & $14.185,6$ \\
Proyectos con impacto directo sobre la pobreza en la región & 312 & 863,5 \\
\hline Participación regional en el total nacional (\%) & 26,3 & 31,4 \\
Proyectos de pobreza en el total regional (\%) & 19,6 & 19,6 \\
\hline
\end{tabular}

Para calcular la participación se excluyen los 28 proyectos de las corporaciones autónomas regionales, por un valor de 44.909.803.251 pesos.

Fuente: SGR (2014b), cálculos propios.

El cuadro 4 muestra los proyectos aprobados por los OCAD y financiados con regalías, en la región y a nivel nacional. E1 26,3\% de los 6.156 proyectos aprobados a nivel nacional fue a la región, y correspondía al $31,4 \%$ del valor aprobado total. La proporción superior a la de la población $(21,4 \%)$ es favorable dado que su participación en el PIB nacional es aún menor. Pero este aspecto positivo poco incide en el combate a la pobreza: solo el 19,6\% de los proyectos aprobados para el Caribe se dirige a combatir directamente la pobreza, y los 312 proyectos reciben apenas el 19,6\% del valor aprobado para financiar inversión, unos 863 mil millones de pesos, 433 millones de dólares a la tasa de cambio del 15 de septiembre de 2014. Esta no es una suma que puede lograr una transformación radical en el paisaje de pobreza; solo equivale al 0,8\% del PIB de la región en 2013 (DANE, 2014a).

Este resultado refleja la forma en que la Ley 1530 de 2012 (que regula el nuevo sistema) clasifica la inversión de las regalías. De los doce criterios para clasificar los posibles proyectos financiados con regalías mencionados en el artículo 27 , solo uno, el tercero, hace referencia expresa a mejoras en el nivel de vida, y los beneficiarios corresponden a grupos étnicos minoritarios específicos, y no a los pobres en general. Este artículo da demasiada libertad para determinar el tipo de proyectos y no es suficientemente preciso para que sea un componente coherente de un plan contra la pobreza. 


\section{EL ARGUMENTO EN PRO DE LA DISTRIBUCIÓN DIRECTA}

E1 análisis de las secciones anteriores lleva a tres conclusiones. 1. E1 nivel de financiación disponible para enfrentar ex ante la pobreza en la región Caribe (y en las demás) es pequeño para esa tarea: la mayoría de los recursos del sistema ya está destinada a otros propósitos antes de dar cabida a la pobreza (por medio del FCR y el FDR). 2. La distribución ex post de los recursos a los municipios de la región solo tiene una relación débil con la incidencia de la pobreza. 3. La inversión ex post de las regalías en proyectos aprobados por los OCAD muestra que los que tienen impacto directo sobre la pobreza son una pequeña minoría. Estos tres puntos indican que aunque el nuevo sistema es más equitativo que el anterior, no tendrá un impacto significativo sobre la pobreza, y menos con la urgencia necesaria. Tenemos entonces que considerar alternativas que podrían tener un impacto mayor e inmediato con recursos similares.

En el resto del mundo aumenta la desilusión con la forma de distribuir y gastar los ingresos fiscales provenientes de recursos no renovables. Primero fue alimentada por la percepción de la "maldición de los recursos", sobre la cual se ha escrito mucho ${ }^{7}$. El argumento es que el ingreso de grandes sumas de dinero en forma de rentas se traduce en ineficiencia, despilfarro y corrupción en el gasto público, en parte porque los gobiernos no han fijado impuestos para obtener estas grandes entradas. Por ello se ha pedido su distribución directa a la ciudadanía para evitar los problemas de alternativas, bien sea que involucren una distribución central, regional o municipal.

E1 tema de este escrito no es la maldición de los recursos como tal. Quizá con el nuevo sistema de distribución de las regalías este asunto sea marginal: puede tener fallas, pero su diseño intenta asegurar que los recursos se distribuyan equitativamente y se gasten eficientemente. Aunque no haya evidencia de esta maldición, eso no implica que se estén gastando para erradicar la pobreza. Y este es el contexto para considerar los méritos de la distribución directa: ¿sería un medio para enfrentar radicalmente la pobreza en la región?

Cabe aclarar que la idea de enfrentar la pobreza mediante la distribución directa de las rentas de la explotación de recursos naturales no es nueva, y tampoco la demostración de su efecto potencial. Segal, por ejemplo, con datos globales de estas rentas y la distribución del ingreso de 2000 a 2006, encontró que, "si cada país en desarrollo implementara la política, el número de personas que vive con menos de

7 Aquí basta mencionar que ese término fue introducido por Richard Auty (1993). Van der Ploeg (2011) revisa esa literatura. 
1 dólar diario podría disminuir entre el 27\% y el 66\%, dependiendo del año y de los supuestos" (2011, 475). Y hay muchos ejemplos de su operación, quizá el más conocido la política del estado de Alaska, que usa su autonomía con respecto a la explotación minera permitida por el sistema federal estadounidense (Goldsmith, 2011). En 1977 su economía fue transformada por la explotación de petróleo del "North Slope” en la Bahía Prudhoe, un descubrimiento gigantesco realizado en 1968. En preparación de la bonanza se estableció el Fondo Permanente de Alaska por plebiscito popular en 1976 que, junto con la Reserva Presupuestal Constitucional, recibiría el 25\% de los ingresos petroleros que se invertirían y pagarían un dividendo anual a todos los residentes. Solo la mitad de los ingresos del fondo se ha pagado a los residentes como dividendos, y la otra mitad se ha reinvertido (ibíd., 5). Goldsmith informa que en 2010 el dividendo fue de 1.281 dólares per cápita, casi dos millones y medio de pesos a la tasa de cambio promedio de 2010.

E1 Fondo Permanente de Alaska es solo una variante de muchas formas posibles de distribución directa. Tiene tres características, es parcial (solo el 25\% de las regalías entra al fondo), indirecta (se distribuye mediante dividendos pagados por un fondo de inversión) y universal (se reparte a todos los residentes, sin destinar fondos a poblaciones específicas). ¿Cuáles son las otras opciones y cuáles sus ventajas y desventajas?

Estas preguntas se pueden responder mencionando escritos publicados por el Centro para el Desarrollo Global, con sede en Washington, quizá la entidad más importante que aboga por la distribución directa. En un trabajo clave, Moss (2011) vislumbra una distribución directa muy diferente de la de Alaska: la distribución directa de efectivo, en su mayoría entre grupos específicos. Esta puede ser completa (repartición de todos los ingresos fiscales del petróleo), directa (transferencia directa a residentes) y no universal (a grupos específicos, usualmente familias pobres). Moss cita a Hanlon et al. (2010), quienes estimaron que en la época de su estudio 45 países utilizaban algún tipo de distribución directa y beneficiaban a 110 millones de familias, y destaca los ejemplos de México (ProgresaOportunidades, que cubre casi un cuarto de su población y hace pagos en efectivo a familias de escasos recursos a cambio de asistencia a la escuela, asistencia a controles médicos y apoyo nutricional) y Brasil (Bolsa Familia, la transferencia de efectivo más grande del mundo, en pagos mensuales a 12 millones de familias si los niños asisten con 
regularidad a la escuela y se dejan vacunar). Colombia tiene un sistema equivalente, Familias en Acción, como veremos.

Mientras que los argumentos a favor de la distribución directa se suelen centrar en que es un antídoto para la maldición de los recursos y una manera de evitar el mal gobierno, hay otros argumentos más positivos. Moss cita la equidad, la rendición de cuentas, la capacidad de ampliar la base tributaria y el hecho de que es el mejor mecanismo para combatir la pobreza:

Es importante señalar que las transferencias en efectivo tendrían beneficios económicos inmediatos y significativos para las familias pobres, y en últimas para el desarrollo. Incluso un pequeño ingreso adicional regular puede representar una diferencia enorme para los más pobres del mundo, permitiendo inversión adicional en nutrición, salud, educación y microempresas. Proporcionar alguna seguridad de ingreso, aunque los pagos sean modestos, permitiría a las familias pobres evitar mecanismos indeseados como la venta de sus bienes. De hecho, es difícil imaginar un servicio público que entregue un ingreso inmediato, del $10 \%$ por ejemplo, a los pobres, salvo las transferencias en efectivo (Moss, 2011, 8).

A estas ventajas, y pensando en la región Caribe, el impacto sobre la demanda local podría ser un estímulo importante para los municipios pobres donde la pobreza persiste desde hace décadas, crearía nuevas oportunidades empresariales y de empleo e incrementaría la capacidad tributaria de las autoridades municipales.

En un trabajo más reciente, Moss y Majerowicz (2013) enfrentan los argumentos en contra de la distribución directa, así como $\mathrm{Pa}-$ lley $(2003)^{8}$. Esos argumentos incluyen la dependencia del pago, la pereza, el uso de los fondos de inversión en infraestructura pública en otros propósitos, posibles consecuencias inflacionarias, una posible actitud negativa hacia los bienes colectivos y quizá un impacto perverso sobre el crecimiento de la población si la distribución es per cápita, incluyendo a los hijos. Tal vez el más convincente sea el posible impacto negativo sobre el gasto en infraestructura. Pero este supone una situación estática, ceteris paribus, pues no tiene en cuenta el aumento del crecimiento y de los ingresos tributarios que generaría una distribución directa sustancial y sostenida.

\section{IMPACTO POTENCIAL SOBRE LA POBREZA EN LA REGIÓN}

En esta sección se ilustra la escala del impacto que la distribución directa del recaudo fiscal por recursos no renovables podría tener sobre la pobreza en la región. Primero, se hacen estimaciones basadas en

${ }^{8}$ E1 Centro para el Desarrollo Global también ha publicado varios estudios de caso sobre la distribución directa, incluido un interesante análisis de sus posibilidades en Venezuela (Rodríguez et al., 2012). 
los ingresos fiscales recibidos por el gobierno nacional en 2011. Este ejercicio no busca contrastar el sistema de distribución anterior con el sistema actual. Su propósito principal es incluir todos los ingresos fiscales, no solo los de regalías: 2011 es el año más reciente para el que hay datos oficiales sobre el impuesto de sociedades de las empresas del sector de recursos no renovables; también hay datos del ingreso por la participación en Ecopetrol y por regalías. Para estas estimaciones se usa el índice de NBI actualizado a 2011. Luego se hace el mismo ejercicio, solo con los datos de regalías en 2013-2014 y con datos de pobreza monetaria, que pese a ser más recientes que los de NBI no incluyen al Archipiélago de San Andrés y Providencia.

\section{DISTRIBUCIÓN DIRECTA DEL INGRESO FISCAL POR RECURSOS NO RENOVABLES EN 2011}

El cuadro 5 muestra la composición de los ingresos fiscales del gobierno nacional provenientes de recursos no renovables, incluidas todas las fuentes: regalías, impuesto de sociedades, dividendos e impuestos al patrimonio, por un total de 31 billones de pesos.

\section{Cuadro 5}

Ingresos fiscales provenientes de recursos no renovables en 2011 (Millones de pesos)

\begin{tabular}{lr}
\hline Sector/rubro & \multicolumn{1}{c}{ Valor } \\
\hline Petróleo y gas & \\
Impuesto de sociedades (todas las de petróleo y gas) & 11.141 .181 \\
Dividendos de Ecopetrol (sobre utilidades del año anterior) & 5.275 .794 \\
Regalías & 8.190 .000 \\
Carbón (carbón de piedra) & \\
Impuesto de sociedades & 1.069 .369 \\
Regalías & 1.268 .653 \\
Otros minerales & \\
Impuesto de sociedades & 103.393 \\
Regalías & 342.793 \\
Impuesto al patrimonio & 3.610 .898 \\
Total & 31.002 .081 \\
Regalías totales & 9.801 .446 \\
Participación de las regalías en el total (\%) & 31,6 \\
\hline Nota: los datos del impuesto al patronio para & petró
\end{tabular}

Notas: los datos del impuesto al patrimonio para el petróleo y el gas natural no estaban disponibles en la DIAN. Pero Ecopetrol publica esos datos y declaró que en 2011 pagó 476.494 millones de pesos por este impuesto. Los ingresos del gobierno por extracción de recursos no renovables serán un poco mayores una vez se incluyan tales impuestos.

Fuentes: Ministerio de Minas y Energía (2012, Anexo Hidrocarburos No. 31, Anexo Minería No. 32 y 33); DIAN (2011a, 2011b); Ecopetrol (2012, 128); Ministerio de Minas y Energía (2013, Sección Regalías, tablas 1 y 4).

De ese total, 24,6 billones, el 79\%, provino del petróleo y el gas natural y 9,8 billones, el 31\%, de regalías. Es necesario considerar todas las fuentes porque, como en este caso, las regalías pueden ser una fuen- 
te minoritaria de ingreso y la división entre ingresos por regalías y otros ingresos por recursos no renovables es arbitraria ${ }^{9}$. Además, al considerar la distribución directa, es necesario establecer claramente los derechos ciudadanos con respecto a los recursos naturales de la nación, y considerar únicamente el ingreso por regalías sería inapropiado porque el gobierno puede cambiar las tasas de regalías a la vez que aumentan los impuestos y otras fuentes de ingreso provenientes de recursos no renovables. El derecho que mencionamos funciona mejor cuando es igual para todos los ciudadanos, como en Alaska, pero en nuestro contexto la preocupación es aliviar la pobreza, y se debe identificar la población objetivo.

Cuadro 6

Población en pobreza extrema y en pobreza región Caribe 2011 (Miles)

\begin{tabular}{|c|c|c|c|c|c|}
\hline \multirow[b]{2}{*}{ Departamento } & \multicolumn{5}{|c|}{ Población } \\
\hline & Total & En pobreza & Porcentaje & Con NBI & Porcentaje \\
\hline Atlántico & $2.344,1$ & 190,8 & 8,1 & 579,9 & 24,7 \\
\hline Bolívar & $2.002,5$ & 467,3 & 23,3 & 933,3 & 46,6 \\
\hline Cesar & 979,1 & 215,6 & 22,0 & 437,9 & 44,7 \\
\hline Córdoba & $1.607,5$ & 486,5 & 30,3 & 949,9 & 59,1 \\
\hline La Guajira & 846,6 & 398,8 & 47,1 & 552,3 & 65,2 \\
\hline Magdalena & $1.212,6$ & 278,9 & 23,0 & 578,2 & 47,7 \\
\hline Sucre & 818,7 & 219,8 & 26,9 & 449,1 & 54,9 \\
\hline San Andrés & 73,9 & 5,1 & 6,9 & 30,2 & 40,8 \\
\hline Región Caribe & $9.885,0$ & $2.262,4$ & 22,9 & $4.510,7$ & 45,6 \\
\hline Nacional & 46.044 .6 & $4.897,6$ & 10,6 & $12.790,6$ & 27,8 \\
\hline \multirow[t]{3}{*}{$\%$ región Caribe } & 21,5 & 46,2 & & 35,3 & \\
\hline & \multicolumn{5}{|c|}{ Hogares } \\
\hline & Número & Tamaño prom & $\begin{array}{ll}\text { edio } & \text { En pc }\end{array}$ & reza extrema & Con NBI \\
\hline Atlántico & 564,0 & & 4,2 & 45,9 & 139,5 \\
\hline Bolívar & 468,5 & & 4,3 & 109,3 & 218,4 \\
\hline Cesar & 235,9 & & 4,2 & 52,0 & 105,5 \\
\hline Córdoba & 361,1 & & 4,5 & 109,3 & 213,4 \\
\hline La Guajira & 177,1 & & 4,8 & 83,4 & 115,5 \\
\hline Magdalena & 280,8 & & 4,3 & 64,5 & 133,9 \\
\hline Sucre & 187,8 & & 4,4 & 50,4 & 103,0 \\
\hline San Andrés & 21,5 & & 3,4 & 1,5 & 8,8 \\
\hline Región Caribe & $2.296,7$ & & 4,3 & 516,3 & 1.038 .0 \\
\hline Nacional & $12.464,1$ & & 3,7 & $1.325,8$ & $3.462,4$ \\
\hline \% región Caribe & 18,4 & & & 38,9 & 30,0 \\
\hline
\end{tabular}

Fuente: DANE (2014b, 2014c).

El cuadro 6 presenta las estimaciones de la población total, en pobreza y en pobreza extrema del DANE. Como ya se señaló, estos son los

${ }^{9}$ Cabe señalar que el recaudo bruto del Estado entre las empresas productoras de recursos naturales no es igual al recaudo neto. Espitia (2013) encuentra que entre 2004 y 2011 en el subsector de metales preciosos, por cada peso que las empresas pagaban en regalías, el Estado les devolvía dos en deducciones tributarias. 
mejores datos disponibles, y su uso no es tan problemático en este contexto porque si la pobreza se ha reducido el impacto potencial de la distribución directa sería aún mayor. Mientras que los departamentos de la región Caribe tenían el 21,5\% de la población total en 2011, el 35\% de la población con necesidades básicas insatisfechas vivía en esos departamentos. Sin embargo, una alta proporción de la población nacional que vivía en la "miseria" o en pobreza extrema, el 46\%, habitaba en esta región. Esa es la esencia del problema: una concentración mayor de personas pobres, algunas en circunstancias de desesperación, en un país de "ingreso medio alto" (Banco Mundial, 2014). A continuación se estima el impacto potencial de la distribución directa.

Cuadro 7

Distribución directa de los ingresos fiscales y las regalías en la región, 2011 Pobreza extrema y pobreza según NBI

\begin{tabular}{|c|c|c|}
\hline Categoría & Pobreza extrema & Pobreza \\
\hline \multicolumn{3}{|c|}{ Ingresos fiscales } \\
\hline $\begin{array}{l}\text { Asignación según la población en pobreza extrema } \\
\text { (millones de pesos) }\end{array}$ & 14.321 .250 & 10.933 .136 \\
\hline Per cápita anual (pesos) & 6.330 .055 & 2.423 .811 \\
\hline Per cápita mensual (pesos) & 527.505 & 201.984 \\
\hline Por hogar anual (pesos) & 27.244 .467 & 10.432 .049 \\
\hline Por hogar mensual (pesos) & 2.270 .372 & 869.337 \\
\hline \multicolumn{3}{|l|}{ Regalias } \\
\hline $\begin{array}{l}\text { Asignación según la población en pobreza extrema } \\
\text { (millones de pesos) }\end{array}$ & 4.527 .727 & 3.456 .560 \\
\hline Per cápita anual (pesos) & 2.001 .275 & 766.299 \\
\hline Per cápita mensual (pesos) & 166.773 & 63.858 \\
\hline Por hogar anual (pesos) & 8.613 .460 & 3.298 .139 \\
\hline Por hogar mensual (pesos) & 717.788 & 274.845 \\
\hline
\end{tabular}

Fuente: cálculos de los autores.

En el cuadro 7 se presenta la suma de dinero que habrían recibido los hogares en pobreza extrema o en pobreza en 2011, mediante una distribución directa, usando su tamaño promedio de 2011. Para la cantidad total que habría estado disponible para esa distribución se usan los ingresos fiscales por recursos no renovables y la parte correspondiente a regalías. La asignación a la región es proporcional a las personas en pobreza extrema o en pobreza que allí vivían en ese año. Considerando los ingresos fiscales, los hogares en situación de pobreza extrema habrían recibido algo más de 2,27 millones de pesos mensuales y los hogares pobres un poco más de 869 mil pesos. Considerando únicamente las regalías, las cifras se reducen a $717 \mathrm{mil}$ pesos y a 275 mil pesos. Puesto que el salario mínimo mensual era de 535 mil pesos, los hogares en extrema pobreza habrían recibido 
una suma superior y los hogares en pobreza una suma menor pero aún significativa (más de medio salario mínimo). Es decir, tomando solamente las regalías, la distribución directa habría podido sacar de la pobreza extrema a los hogares de la región.

\section{DISTRIBUCIÓN DIRECTA EN 2013}

En este ejercicio se usan datos diferentes pero más recientes. 1.Puesto que no se dispone de datos del impuesto de las sociedades de recursos no renovables en 2013, solo se tendrá en cuenta el componente de regalías. 2. Como el ingreso por regalías de 2013 se reporta junto con el de 2014, dividimos el total de 2013-2014 por dos para llegar a la suma potencialmente disponible para distribución directa en 2013. 3. Los datos de pobreza se refieren a la "pobreza monetaria", pues solo tienen en cuenta el ingreso monetario reportado por la Gran Encuesta Integrada de Hogares 2008-2012 y no otros aspectos, como el acceso a servicios públicos. 4. Estos datos muestran la diferencia entre "pobreza" y "pobreza extrema" según los umbrales de ingreso mensual del cuadro 8.

Como se ve en el cuadro, el umbral de pobreza extrema es muy bajo, unos 90 mil pesos mensuales, y el de pobreza poco más de un tercio del salario mínimo, que era de 589.500 pesos en 2013 (Banco de la República, 2014b). Dado que son muy bajos, muchos sostendrían que un umbral de pobreza de unos 200 mil pesos mensuales es más apropiado para indicar el comienzo de la pobreza extrema y que un umbral de pobreza extrema de unos de 3.000 pesos diarios no permite sobrevivir, salvo por muy corto tiempo.

Teniendo en cuenta estas limitaciones, el cuadro 9 sintetiza el mismo ejercicio del cuadro 7 , con resultados diferentes: la distribución directa del ingreso solo daría algo más de un salario mínimo a los hogares en pobreza extrema y cerca de un tercio de un salario mínimo si se distribuyera a todos los hogares en pobreza. ¿Por qué estos resultados son más bajos que los del cuadro 7? Hay varias razones: el monto disponible del SGR en 2013 fue menor que en 2011 (8,4 billones de pesos frente a 9,8). Debido a las diferentes medidas de la pobreza utilizadas en 2013, el número de personas en pobreza extrema disminuyó, mientras que el de personas en pobreza aumentó (a nivel nacional). La reducción de las primeras contrarrestó el impacto per cápita del descenso del total de regalías disponibles. El aumento de las segundas reforzó el impacto per cápita del menor nivel total de regalías disponibles para distribuir en forma directa a los hogares 
pobres. En la región Caribe la reducción del tamaño promedio del hogar redujo el monto disponible por hogar.

Cuadro 8

Población en pobreza extrema y pobreza, región Caribe, 2013

(Pobreza monetaria)

(Miles de habitantes y pesos mensuales)

\begin{tabular}{lcccc}
\hline Departamento & Población & $\begin{array}{c}\text { Línea de } \\
\text { pobreza extrema }\end{array}$ & $\begin{array}{c}\text { En pobreza } \\
\text { extrema }\end{array}$ & Porcentaje \\
\hline Atlántico & $2.402,9$ & 97.243 & 103,3 & 4,3 \\
Bolívar & $2.049,1$ & 93.391 & 258,2 & 12,6 \\
Cesar & $1.004,1$ & 91.928 & 125,5 & 12,5 \\
Córdoba & $1.658,1$ & 86.784 & 308,4 & 18,6 \\
La Guajira & 902,4 & 87.630 & 231,9 & 25,7 \\
Magdalena & $1.235,5$ & 91.366 & 192,7 & 15,6 \\
Sucre & 834,9 & 90.493 & 84,3 & 10,1 \\
Región* & $10.087,0$ & 92.074 & $1.304,3$ & 12,9 \\
\hline Nacional & $47.121,1$ & 91.698 & $4.288,0$ & 9,1 \\
Región (\%) & 21,4 & & 30,4 & \\
\hline
\end{tabular}

\begin{tabular}{lccccc}
\hline & $\begin{array}{c}\text { Línea de } \\
\text { pobreza }\end{array}$ & En pobreza & Porcentaje & $\begin{array}{c}\text { Tamaño } \\
\text { promedio } \\
\text { del hogar }\end{array}$ & $\begin{array}{c}\text { Hogares en } \\
\text { pobreza }\end{array}$ \\
\hline Atlántico & 224.649 & 778,5 & 32,4 & 4,1 & 190,8 \\
Bolívar & 208.950 & 856,5 & 41,8 & 4,0 & 214,7 \\
Cesar & 205.365 & 449,8 & 44,8 & 3,7 & 120,6 \\
Córdoba & 183.799 & 858,9 & 51,8 & 4,1 & 211,0 \\
La Guajira & 185.533 & 503,5 & 55,8 & 4,0 & 126,8 \\
Magdalena & 202.003 & 623,9 & 50,5 & 4,1 & 151,8 \\
Sucre & 196.599 & 394,9 & 47,3 & 4,0 & 98,2 \\
Región* & 1.406 .898 & $4.466,0$ & 47,3 & 4,0 & $1.112,6$ \\
\hline Nacional & 206.091 & $14.419,0$ & 30,6 & 3,5 & $4.119,7$ \\
Región (\%) & & 31,0 & & & \\
\hline
\end{tabular}

* No hay datos disponibles para el Archipiélago de San Andrés y Providencia.

Fuente: DANE (2014b, 2014d).

Cuadro 9

Distribución potencial directa de las regalías, región Caribe 2013

\begin{tabular}{lrr}
\hline Categoría & Pobreza extrema & \multicolumn{1}{c}{ Pobreza } \\
\hline Regalías estimadas para 2013 (millones de pesos) & 8.375 .649 & 8.375 .649 \\
Asignación a la región según la población en pobreza ex- & 2.547 .843 & 2.594 .273 \\
trema (millones de pesos) & 1.953 .268 & 580.874 \\
Per cápita anual (pesos) & 162.772 & 48.406 \\
Per cápita mensual (pesos) & 7.840 .616 & 2.331 .686 \\
Por hogar anual (pesos) & 653.385 & 194.307 \\
\hline
\end{tabular}

Fuente: cálculos de los autores.

Hay, por supuesto, otros temas de equidad asociados con la distribución directa, especialmente cuando no es universal. Si es universal, como en Alaska, toda la población se beneficia de un mismo divi- 
dendo, sin importar su nivel de ingresos. El propósito de este trabajo es demostrar el impacto potencial de una distribución focalizada, para sacar de la pobreza a una buena proporción de la población de la región. Podría ocurrir que personas que trabajan por un salario mínimo y otras que no trabajan reciban un pago directo similar que desincentive el trabajo. Pero esto se podría superar al menos de dos maneras.

1. En vez de distribuir dinero en efectivo se podrían distribuir bienes de capital, incluida la inversión en capital humano familiar. Se podrían repartir herramientas y materiales de construcción, junto con la capacitación para mejorar la vivienda. Con solo un salario mínimo en tales materiales, por ejemplo, se compraría arena y cemento suficientes para instalar pisos de concreto al menos en dos cuartos o mejorar el exterior de casas modestas. Durante un año, tal distribución transformaría viviendas casi inhabitables en alojamientos dignos, con instalaciones sanitarias y cableado eléctrico seguro. $\mathrm{Y}$ esas inversiones estimularían la actividad económica en las comunidades pobres.

2. Se podría focalizar la distribución directa para fortalecer el sistema existente de transferencias a familias pobres, Familias en Acción, que en 2014 hacía un pago mensual de 71.400 pesos a familias de categoría 4 (de las comunidades más pobres) con al menos un hijo menor de 7 años, y de 61.200 pesos a familias de las demás categorías. Ese pago depende de la asistencia de los hijos a los chequeos de salud regulares del programa Crecimiento y Desarrollo. Hay, además, un pago adicional mensual por hijo que asista a la escuela, que aumenta según la categoría y el año escolar del hijo (Familias en Acción, 2014). Según un reciente estudio internacional publicado en British Medical Journal, Familias en Acción ha tenido éxito para promover el desarrollo de la niñez (Attanasio et al., 2014). En 2014 su presupuesto total a nivel nacional fue de 1,8 billones de pesos y benefició a 2,7 millones de familias vulnerables o desplazadas, y a 120.000 jóvenes (Ministerio de Hacienda, 2014, 149). De acuerdo con nuestras estimaciones, en la región Caribe hay cerca de un millón cien mil hogares en situación de pobreza monetaria, y si las regalías a las que tenía derecho en 2013 se hubiesen entregado a estos hogares, cada uno habría recibido 194 mil pesos por mes. Es posible entonces aumentar en forma significativa el pago básico de Familias en Acción y dedicar la mayoría de las regalías a otros propósitos. 


\section{CONCLUSIONES}

En nuestra investigación se encontró evidencia que ratifica, con datos de 2012 a 2014, que el nuevo sistema de regalías ha tenido poco impacto sobre la pobreza en la región Caribe. Este resultado era en parte predecible por su diseño, que asigna pocos recursos a su alivio directo, y ha sido confirmado por su operación. Hay una relación débil entre regalías a los municipios e incidencia de la pobreza. Y solo una pequeña minoría de los proyectos aprobados para financiar con regalías tiene impacto directo sobre la pobreza.

En contraste, la distribución directa de esos mismos recursos podría haber sacado de la pobreza a la gran mayoría de la población pobre, aun usando la pobreza monetaria y no el índice de NBI para esa distribución, y restringiéndola a las regalías, sin tener en cuenta todos los ingresos fiscales provenientes de recursos no renovables. Hay recursos suficientes para reducir drásticamente la pobreza.

Parece razonable el argumento de que los ingresos recibidos por agotamiento de recursos no renovables no se deben gastar en consumo inmediato individual, y que se debe incluir un componente de reinversión, enfrentando siempre la situación de pobreza. Para lograr un balance entre el poder adquisitivo adicional que las comunidades pobres necesitan desesperadamente y evitar el impacto adverso sobre los incentivos se sugiere un paquete con tres componentes. 1. Reconociendo que los 312 proyectos financiados con regalías que tienen un impacto directo sobre las necesidades básicas insatisfechas son valiosos como herramientas contra la pobreza, debe haber un elemento de infraestructura, dirigido contra la pobreza, en la inversión de las regalías. 2. Debería aumentar la distribución directa de efectivo a los hogares pobres: dado el éxito de Familias en Acción, los beneficios de ese esquema deberían aumentar. 3. Debería existir una segunda modalidad de distribución directa, como pequeñas sumas de capital en especie a los hogares pobres para ayudarlos a mejorar su vivienda. Ese tipo de transferencia de capital es consistente con las investigaciones que demuestran que la distribución sumamente desigual de los activos es la causa de la desigualdad de ingresos y de la pobreza (Piketty, 2014). Y se podrían condicionar así como hace Familias en Acción en beneficio del desarrollo de la juventud. Todo ello se podría hacer usando las regalías de una manera muy diferente. La caída de los precios del petróleo no sería una razón para no probar esta opción; indica más bien que, con menores ingresos por regalías, es el momento de concentrarlos en un solo fin.

Una limitación de este trabajo es que el análisis de los proyectos con impacto directo sobre la pobreza no tiene en cuenta la etapa 
en que se encuentra el proyecto y tampoco si el dinero destinado a financiarlos se está usando correctamente; de no ser así estaríamos sobreestimando el monto que realmente recibe la población pobre. Además, según la Contraloría General de la República (2014), entre 2012 y 2014, hubo una baja ejecución de las regalías, lo que también sobreestima su impacto.

Cuando se diseñaba el nuevo sistema de regalías, Antonio Hernández Gamarra anticipó y criticó ese diseño porque era anti-pobre y anti-rural. "Lo deseable por hacer", escribió, "sería establecer prioridades y distribuir los recursos según las carencias en las necesidades básicas en cada departamento" $(2011,2)$. Lo que aquí se propone es una opción razonable para intentarlo, pues la pobreza es la prioridad más urgente en la región Caribe.

\section{REFERENCIAS BIBLIOGRÁFICAS}

1. Acosta, A. La reforma al régimen de regalias y su impacto en las finanzas territoriales, Bogotá, Litografía Impregnon, 2012.

2. Acto Legislativo 05 de 2011, [https://www.sgr.gov.co/LinkClick.asp $\mathrm{x}$ ?fileticket=E9g2P8ImArE\%3d\&tabid=95\&mid=517].

3. Attanasio, O. et al. "Using the infrastructure of a conditional cash transfer program to deliver a scalable integrated early child development program in Colombia: Cluster randomized controlled trial", British Medical Journal 349, 5785, 29 de septiembre de 2014.

4. Auty, R. M. Sustaining development in mineral economies: The resource curse, Londres y Nueva York, Routledge, 1993.

5. Banco de la Republica. "Promedios anuales o tasas de cambio diarias", 2014a, [http://www.banrep.gov.co].

6. Banco de la Republica. "Salario mínimo legal en Colombia 19842014”, 2014b, [http://www.banrep.gov.co].

7. Bonet, J. y Urrego, J. “E1 Sistema General de Regalías: ¿mejoró, empeoró o quedó igual?”, documento de trabajo sobre economía regional n. ${ }^{\circ}$ 198, Banco de la República, CEER, 2014.

8. Candelo, R. et al. "Las regalías en Colombia y su impacto en el ámbito subnacional”, Desafíos 22, 1, 2010, pp. 143-203.

9. Contraloría General de la República. "Regalías: baja ejecución y altos saldos en Bancos", Informes de Evaluación y Seguimiento Control. Macro Regalias, 2015.

10. Cuéllar, M. y D. Castellanos. "Reforma a las regalías: ¿hacia una menor disparidad regional?", Semana Económica 795, 2011.

11. DANE. “Cuentas Departamentales”, 2014a, [https://www,dane,gov,co/ index, php/pib-cuentas-nacionales/cuentas-departamentales].

12. DANE "Proyecciones de población 1985-2020", 2014b, [http:// www, dane,gov,co/files/investigaciones/fichas/Ficha_Estimaciones_Proyecciones_85_2020.pdf]. 
13. DANE. "Necesidades básicas insatisfechas", 2014c, [http://www.dane. gov.co/index.php/estadisticas-sociales/necesidades-basicas-insatisfechas-nbi].

14. DANE. "Cifras departamentales de pobreza monetaria y desigualdad 2013", 2014d, [http://www.dane.gov.co/index.php/estadisticas-sociales/ pobreza].

15. DIAN. "Recaudo renta de sociedades", 2011a, [http://www.dian.gov. co/contenidos/cifras/estadisticas.html].

16. DIAN. "Recaudo impuesto de patrimonio", 2011b, [http://www.dian. gov.co/contenidos/cifras/estadisticas.html].

17. DNP. "Evaluación de la distribución de recursos del Fondo Nacional de Regalías y nueva propuesta de priorización”, CONPES, documento No. 3523, 2008.

18. Echeverry, J. et al. "Por qué es necesaria la creación de un Sistema General de Regalías”, Notas Fiscales 2, Ministerio de Hacienda y Crédito Público, 2011.

19. Ecopetrol. Informe Anual, 2012, [http://www.ecopetrol.com.co].

20. Espitia, J. E. "Las regalías y los descuentos tributarios en la explotación de metales preciosos", Vox Populi 12, 2013, pp. 39-50.

21. Familias en Acción. 2014, [http://www.dps,gov.co/Ingreso_Social/ Familiasen Accion,aspx].

22. Galvis, L. y Meisel, A. "Persistencia de las desigualdades en Colombia: Un análisis espacial”, documento de trabajo sobre economía regional n. ${ }^{\circ}$ 120, Banco de la República, 2010.

23. Garcés, J. y J. Espitia. “Análisis de agrupaciones departamentales y municipales en Colombia para el periodo 1993-2005, identificadas a partir de indicadores relacionados con regalías", Administración $\mathcal{E}^{\circ}$ Desarrollo 37, 54, 2009, pp. 81-107.

24. Goldsmith, S. "The Alaska Permanent Fund Dividend: A case study in the direct distribution of resource rent”, Anchorage, Institute of Social and Economic Research, University of Alaska, 2011.

25. Hanlon, J.; A. Barrientos y D. Hulme. Just give money to the poor, Sterling, Kumarian Press, 2010.

26. Hernández G., A. "Regalías y desarrollo regional”, documento de trabajo, Observatorio del Caribe Colombiano, 2010.

27. Hernández G., A. "El sesgo anti pobres (y anti rural) de la ponencia sobre la Ley de Regalías”, manuscrito inédito facilitado a los autores, 2011.

28. Ley 1530 de 2012, [https://www.sgr.gov.co/LinkClick.aspx?fileticket $=\mathrm{EZ}$ ij8T5b0Jc\%3d\&tabid=95\&mid=517].

29. Ministerio de Hacienda. "Presupuesto General de la Nación 2014", 2014, [http://www.minhacienda.gov.co/portal/page/portal/HomeMinhacienda/presupuestogeneraldelanacion/ProyectoPGN/2014/PRESUPUESTO\%20GRAL\%202014.pdf].

30. Ministerio de Minas y Energía. "Memorias al Congreso de la República 2010-2011”, sección Regalías, Bogotá, 2011.

31. Mollar, L. "Breaking with history: Why Colombia needs a more progressive tax system”, Colombia Reports, World Bank, 17 de diciembre de 2012. 
32. Moss, T. y S. Majerowicz. “Oil-to-cash won't work here: Ten common objections", Center for Global Development, policy paper 024, Washington, 2013.

33. Moss, T. "Oil to cash: Fighting the resource curse through cash transfers", Center for Global Development, working paper 237, Washington, 2011.

34. Palley, T. "Combating the natural resource curse with citizen revenue distribution funds: Oil and the case of Iraq", Foreign Policy in Focus, Special Report, 2003.

35. Piketty, T. Capital in the Twenty First Century, Cambridge, Mass., Harvard University Press, 2014.

36. Rodríguez, P.; J. Morales y F. Monaldi. "Direct distribution of oil revenues in Venezuela: A viable alternative?", Center for Global Development, working paper 306, Washington, 2012.

37. Rojas, J. "Sobre el efecto de las regalías en el bienestar: una revisión del periodo 2001-2011”, Archivos de Economía, documento 414, 2014.

38. Segal, P. "Resource rents, redistribution and halving global poverty: The resource dividend", World Development 39, 4, 2011, pp. 475-489.

39. SGR. "Distribución recursos del SGR vigencia 2012 y vigencia 20132014”, 2014a, [www.sgr.gov.co].

40. SGR. "Relación de proyectos aprobados y/o cargados a GESPROYSGR", corte al 15 de septiembre de 2014, 2014b, [www.sgr.gov.co].

41. Van der Ploeg, F. "Natural resources: Curse or blessing", Journal of Economic Literature 49, 2, 2011, pp. 366-420.

42. World Bank. 2014, [http://data,worldbank,org/country/colombia? display=default $]$. 